\title{
Entrevista com Prof. Dr. Gabino la Rosa Corzo
}

Professor e pesquisador cubano, especialista em Arqueologia. Possui graduação em História pela Facultad de Humanidades de la Universidad de La Habana e Doutorado em Ciências Históricas.

Ao longo de sua carreira acadêmica, tem atuado como pesquisador e docente nos níveis de Graduação e Pós-graduação em diferentes universidades cubanas e em outros países. Entre suas experiências profissionais, destacam-se cursos promovidos pelo LAP- NEPAMUNICAMP e pelo IFCH-UNICAMP.

É autor de várias publicações, sendo a mais recente, o livro Tatuados. Deformaciones étnicas de los cimarrones en Cuba (2011).

A entrevista abaixo aborda sua trajetória acadêmica, as especificidades da arqueologia cubana e algumas de suas impressões sobre a relação desta com a arqueologia brasileira, entre outras coisas.

\section{Entrevistadora}

Carola Sepúlveda: Doutoranda em Educação pela UNICAMP, Mestra em Estudos de Gênero e Cultura pela Universidad de Chile e Bacharel e Licenciada em História e Geografia pela Universidad de Santiago de Chile. Bolsista Programa "Becas Chile- Formación de capital humano avanzado en el extranjero" (CONICYT. Gobierno De Chile). carolasepulvedavasquez@,gmail.com

\section{Entrevista}

Entrevistadora: ¿Cómo se autodefine Gabino La Rosa?

Gabino La Rosa: Creo que es una de las preguntas más complejas que me han hecho en mi vida profesional. Generalmente, a los humanos nos gusta definir a los que nos rodean, pero en muy pocas ocasiones emprendemos la tarea de la autodefinición.

Yo creo que en toda autodefinición se enfrentan varios conceptos: lo que somos en realidad, lo que nos gustaría ser y en cierta medida la forma en que los demás nos definen y que nos inclina hacia el acatamiento de determinadas reglas y principios que en definitiva responden al contexto social e histórico en que vivimos. 
La autodefinición pasa por tamices éticos, humanos, políticos sociales, científicos, profesionales, etc. Pero dejando a un lado el sistema de valores personales que me definen como ser humano, que odia las injusticias, respeta las diferencias sociales, étnicas, raciales o de cualquier tipo, ama la naturaleza y la familia; y para simplificar, desde el punto de vista profesional me autodefino como un antropólogo.

Mi vida profesional se ha movido en los terrenos de la historia, la etnohistoria, la etnoarqueología y la arqueología. Aunque siempre al realizar un abordaje a una problemática he tomado como punto de partida y fundamento metodológico la historia, la etnología o la arqueología, siempre, durante el proceso de investigación he recurrido a todas esas esferas del conocimiento, pues me he propuesto como objetivo principal conocer al hombre inmerso en un contexto social y acontecimientos específicos. Y para conocer y describir al hombre no basta con una de estas esferas del conocimiento o disciplina.

E.: En relación a su trayectoria académica, ¿podría identificar algunas experiencias significativas que siente lo habrían motivado a dedicarse a la arqueología y a los temas que actualmente investiga?

G.R.: Es claro que las experiencias personales tienen gran significación en el derrotero profesional de cualquier persona. En mi caso particular, nací en la ciudad de Cárdenas, Provincia de Matanzas, Cuba. Esta ciudad estuvo vinculada de forma significativa a la esclavitud de plantaciones. Por su puerto, salía una parte importante del azúcar que se producía en la región de mayor concentración de esclavos, la Región Habana-Matanzas.

Esto determinó la existencia de una composición racial y cultural extremadamente rica y compleja en esta ciudad. Yo asistí a la escuela pública y parte de mis amigos de infancia eran descendientes de antiguas familias esclavas. Vivían en condiciones económicas y sociales inferiores al resto de mis compañeros de colegio. Esos grupos y familias mantenían tradiciones que diferían de las restantes y se encontraban limitados en sus espacios y alcances. Estas relaciones crearon el basamento ético que se incorporó a mis intereses profesionales. Cuando inicié mis estudios universitarios en la Facultad de Historia de la Universidad de la Habana en el año de 1962, y aunque esos estudios respondían a conceptos renovadores gracias a la Reforma Universitaria emprendida por la Revolución Cubana, aún estaban saturados de conceptos y valores de la antigua universidad y aunque, por ejemplo, en el terreno de la esclavitud se hicieron verdaderos aportes al conocimiento, la cuestión de las 
formas en que los esclavos se resistieron o combatieron al sistema esclavista eran aún un terreno prácticamente virgen.

Puedo ponerte, por ejemplo, que en Cuba eran conocidos los quilombos de los Palmares (pues existía una bibliografía internacional al respecto), pero no se conocía nada de los quilombos en Cuba. Pero esa situación varió pronto, gracias a los estudios históricos de amigos como José Luciano Franco y algunos otros. Mi mayor satisfacción es haber contribuido a partir de la aplicación de la arqueología y la etnología a ese proceso de conocimiento de esa realidad.

E.: Según su opinión ¿cuáles son las posibilidades que permitiría el incorporar abordajes interdisciplinares a los estudios de base arqueológica?

G.R.: La realidad es muy compleja y dinámica. Para conocerla, sobre todo en sus manifestaciones pasadas, es necesario el abordaje interdisciplinario. Las dos cuestiones que definen esa posibilidad son: la comprensión por parte del investigador de esa complejidad y la existencia de laboratorios y equipos de profesionales de diferentes disciplinas dispuestos a colaborar y enriquecer mutuamente sus campos de acción.

E.: De acuerdo a su experiencia, ¿cómo evalúa el estado actual de las relaciones entre arqueólogos(as) brasileros(as) y cubanos(as)? y ¿qué posibilidades de diálogo académico usted cree que podrían desarrollarse entre las comunidades científicas de ambos países?

G.R.: Creo que estamos en un momento importante de las relaciones y las posibilidades de diálogo académico entre profesionales de Brasil y Cuba. A pesar de las diferencias geográficas y de otro tipo, los puntos de coincidencia en el desarrollo histórico y la conformación de fenómenos sociales paralelos como lo son la esclavitud de plantaciones, la resistencia esclava, la composición étnica, la religiosidad popular, etc., hacen muy rico el diálogo.

Estoy convencido que ya se ha iniciado un proceso de intercambio académico en el plano de las agendas y las personalidades, que solo necesitan el apoyo institucional para un mejor desenvolvimiento.

E.: De acuerdo a su experiencia, ¿cuáles serían las especificidades de la arqueología cubana? 
G.R.: Bueno, este es uno de los terrenos más críticos en la actualidad en Cuba en el terreno de las disciplinas científicas, lo que contrasta con el desarrollo alcanzado en otras esferas de la investigación. Desdichadamente, y a diferencia de la gran mayoría de las naciones latinoamericanas, Cuba carece de una formación académica adecuada dentro del campo de la arqueología, pues las autoridades competentes han negado reiteradamente la posibilidad de la creación de una carrera de grado en esta especialidad. El reducido grupo de arqueólogos profesionales que han trabajado en los últimos 40 años han sido egresados de otras disciplinas universitarias, que han devenido en arqueólogos gracias a la formación posgraduada, a la realización de maestrías y doctorados.

Pero, contradictoriamente, en el país ocupa un lugar cimero el rescate, conservación y manejo del patrimonio cultural en general, lo que demanda la existencia de este tipo de profesionales, por lo que se ha recurrido a la formación de cursos emergentes en Escuelas Talleres, en las que mediante cursos de dos años, jóvenes interesados en la arqueología se forman como obreros calificados para enfrentar las complejas labores del rescate arqueológico de la riqueza patrimonial.

Esto ha producido un vacío profesional en el que las primeras generaciones de arqueólogos que se habían formado por la vía anterior, ya abandonan la profesión, fundamentalmente por razones de edad o fallecimiento, mientras las nuevas generaciones que enfrentan el trabajo carecen de una formación adecuada y cometen no pocos deslices en el terreno de la teoría y la metodología.

Así, puede afirmarse que se ha iniciado un proceso en el que el desnivel de la arqueología cubana en comparación con la restante del continente es cada vez más ostensible.

E.: En una entrevista que usted concedió por el lanzamiento de su libro "Tatuados. Deformaciones étnicas de los cimarrones en Cuba" en Casa del Alba Cultural ${ }^{1}$, usted señala que el tatuaje representa para algunas etnias y tribus, entre ellas algunas africanas, una forma de identificación, donde se establecen semejanzas y diferencias. En esa misma entrevista usted señala que estos estudios sobre tatuajes lo han acompañado por más de veinte años. Si recuperásemos la imagen del tatuaje que usted trabaja y la trasladásemos para hacer una lectura de su trabajo ¿cómo definiría usted el significado de esta línea de investigación para usted? ¿Siente que le ha permitido identificarse, acercarse a otros trabajos o investigadores(as)

\footnotetext{
${ }^{1} \mathrm{http}: / /$ www.ffo.cult.cu/index.php?option=com_content\&view=article\&id=161:entrevista-a-gabino-delarosa\&catid $=67$ :otros
} 
e o diferenciarse? ¿Estudiar estas temáticas ha significado para usted una especie de tatuaje en términos metafóricos?

G.R.: Mi último libro (desde el punto de vista editorial) aborda los tatuajes de los cimarrones en Cuba. Dada la complejidad del tema y la casi nula existencia de fuentes confiables, fue un tema sobre el cual estuve acumulando información a lo largo de los años en que trabajaba en otros proyectos y producía otros textos.

El haber podido recatar los mensajes de los cuerpos de los individuos que se revelaron al sistema esclavista y comprobar que en la actualidad esos tatuajes (escarificaciones) constituyen símbolos de identidad étnica, hace que sea mi libro más estimado. Si a esto se suma el calor con que fue acogida su edición, y la opinión de colegas como Miguel Barnet, presidente de la Unión de Escritores y Artistas de Cuba; Carmen Barcia, Profesora de Mérito de la Universidad de la Habana; Michael Zeuske y Christian Cwik, ambos de la Universidad de Colonia en Alemania, puedo confesarte que "Tatuados" me ha marcado, me ha autoidentificado. 